\title{
The altitudinal variability and temporal instability of the climate- tree-ring growth relationships for Changbai larch (Larix olgensis Henry) in the Changbai mountains area, Jilin, Northeastern China
}

\author{
Chenchen Shen ${ }^{1,2} \cdot$ Lily Wang ${ }^{1} \cdot$ Mingyong $\mathrm{Li}^{1,2}$
}

Received: 5 January 2015/Revised: 5 November 2015/Accepted: 15 November 2015/Published online: 8 December 2015 (C) Springer-Verlag Berlin Heidelberg 2015

\begin{abstract}
Key message We investigated the variability of the relationships between climate and tree-ring growth along an altitudinal gradient and the temporal instability of the relationships under warming for Changbai larch (Larix olgensis Henry) in northeast of China.

Abstract Growth response of trees to climate has been found to vary with elevation, but their relationships might also be altered with ongoing global climate change. We developed residual chronologies of tree-ring growth parameters at three sites to investigate variability of the interactions between climate and tree-ring growth for Changbai larch (Larix olgensis Henry) along an altitudinal gradient on the northern slopes of the Changbai Mountains area in Northeastern China. The results indicate that temperature and precipitation are linked differently to the formation of the annual ring width of Changbai larch at different elevations. Tree-ring density of Changbai larch is mainly positively associated with temperature while negatively responding to precipitation. The relationships between temperature and tree-ring growth became unstable, however, after the notable warming of the late 1980s in
\end{abstract}

Communicated by S. Masaka.

Lily Wang

wangll@igsnrr.ac.cn

Chenchen Shen

shencc.12b@igsnrr.ac.cn

1 Key Laboratory of Land Surface Pattern and Simulation, Institute of Geographical Sciences and Natural Resources Research, Chinese Academy of Sciences, Beijing 100101, China

2 University of Chinese Academy of Sciences, Beijing 100049, China the study area. Tree-ring width decreased at low elevation under drought stress, whereas showed more positive sensitivity to warming at higher altitudes. We found that the tree-ring density relationship with temperature also became unstable under the rising temperature regime. These findings could be applied in simulating tree-ring growth and forest distribution under various climatic and environmental scenarios.

Keywords Tree-ring growth · Dendroclimatic method . Altitudinal variability and temporal instability . Climate change · Larix olgensis Henry

\section{Introduction}

Tree-ring width and density series are both effective indicators of environmental and climatic conditions (Fritts 1976; Wang et al. 2010). Climate change during recent decades has been found to play a role in altering forest composition and structure on regional as well as global scales (Allen et al. 2010; Anderegg et al. 2013; Magnin et al. 2014). Fritts (1976) reported that tree growth is more affected by mean temperature close to the treeline than that at low elevations, where precipitation is more influential. Studies have shown that tree-ring width is significantly correlated to minimum temperature at high elevations (Peterson and Peterson 2001; Dittmar et al. 2003; Yu et al. 2013). Increases in temperature are known to affect forest composition and distribution through drought stress, especially at middle and high latitudes of the Northern Hemisphere (Serreae et al. 2000; Walther et al. 2002; D'Arrigo et al. 2007; Mérian et al. 2011). Instability of the relationships between tree growth and climatic factors (especially temperature), such as the increase, reduction or even 
loss of sensitivity has been observed in recent decades (Biondi 2000; D'Arrigo et al. 2007; Zhang and Wilmking 2010). Other studies have reported that trees growing at the same site or area respond differently to climatic factors near treelines (Lloyd and Fastie 2002; Driscoll et al. 2005; Salzer et al. 2009). Hypotheses like "divergence problem" and "growth divergence" were proposed to account for the variation, and even instability, of the climate-growth relationships. Drought stress caused by rising temperature might be the biggest limitation on tree growth at different altitudes. The northeastern region is the largest area still covered by natural forest in China. Nevertheless, it has also become one of the fastest warming regions in China in recent decades (Ding et al. 2006). In the context of recent global climate change, it is of great concern to study how forest growth response varies with elevation in northeastern China.

Changbai larch (Larix olgensis Henry) is a Chinese conifer grown as a significant timber species in northeastern China (SFA 2008). Changbai larch habitat ranges from 500 to $1950 \mathrm{~m}$ above the sea level (a.s.l.) on the northern slopes of the Changbai Mountains (Wang et al. 1980). Previous studies showed that climatic factors affected treering width of Changbai larch in various ways at different elevations, i.e., Changbai larch was found to suffer more from water stress at lower altitudes and from heat stress at higher altitudes (Wu and Shao 1996; Shao and Wu 1997; Zhu et al. 2009). However, other relationships were also reported. For example, in some studies, tree-ring growth of Changbai larch was significantly negatively correlated to temperature in the previous winter at low elevations while displayed no significant correlations with precipitation $(\mathrm{Yu}$ et al. 2005; Chen et al. 2011). Although these findings are sometimes contradictory, most of these studies were based only on total ring width. Maximum densities of Changbai larch were found to show similar significant correlations with temperature at different elevations (Sun et al. 2012). In a study of another species in the Changbai Mountains, Korean pine, Yu et al. (2013) also found that the effects of climatic conditions on radial growth for Korean pine became stronger because of rising temperature in late 20th century. The result indicated that warming had significantly influenced tree growth in this area. As an important species in the Changbai Mountains area, Changabi larch merits more complete assessment of its growth response to global warming.

In this study, the dendroclimatic approach was applied to: (1) develop chronologies of total ring width and latewood maximum density using data from Changbai larch sites at different elevations; (2) identify the most significant climatic variables influencing tree-ring growth for Changbai larch with increasing elevation; (3) assess the variability of climate-tree-ring growth relationships in recent decades along an altitudinal gradient; (4) investigate the recent temporal instability problem in the climate-tree-ring growth relationships under warming.

\section{Materials and methods}

\section{Study area and climate}

The study was conducted on the northern slopes of the Changbai Mountains in Jilin Province, northeastern China (Fig. 1). The vegetation has a typical zonal pattern in this region (Wang et al. 1980; Hao et al. 2001). Three main forest zones have been recognized during field observations: broad-leaf and Korean pine mixed forest (700-1100 m a.s.l.), dark coniferous forest with spruce and fir as dominant species (1100-1800 m a.s.l.), and subalpine Betula ermanii birch forest (1800-2000 m a.s.1.). Changbai larch is an endemic species distributed widely across the three forest zones of the Changbai Mountains area.

The study area features warm temperate climate with cool, moist summer and long, cold winter. Mountain vegetation displays clear spatial zonality in this area. This makes the Changbai Mountains area an ideal research base for the study of the variability of climate-tree-ring growth relationships. Five meteorological stations around the study area are Erdao (Donggang) Station $\left(42^{\circ} 06^{\prime} \mathrm{N}, 127^{\circ} 34^{\prime} \mathrm{E}\right)$, Tianchi Station $\left(42^{\circ} 01^{\prime} \mathrm{N}, 128^{\circ} 05^{\prime} \mathrm{E}\right)$, Changbai Station $\left(41^{\circ} 25^{\prime} \mathrm{N}, \quad 128^{\circ} 11^{\prime} \mathrm{E}\right)$, Songjiang Station $\left(42^{\circ} 32^{\prime} \mathrm{N}\right.$, $128^{\circ} 15^{\prime} \mathrm{E}$ ), and Yanji Station $\left(42^{\circ} 52^{\prime} \mathrm{N}, 129^{\circ} 30^{\prime} \mathrm{E}\right)$ (Fig. 1). Climatic data (i.e., monthly temperature and precipitation) from these stations were acquired for the period from 1958 to 2008. All climatic data from the stations were checked through the Standard Normal Homogeneity Test (Alexandersson and Moberg 1997). The data of Yanji Station were excluded because the annual trend in precipitation was different from the others. Data of the other four stations had no abrupt variations and the correlations between monthly variables were significant $(p<0.01)$. The data of Tianchi Station, however, were also dropped because the seasonal measurements of climate variables were only available starting in 1989. Consequently, the average climatic values of the remaining three stations were used in this study (Fig. 2).

\section{Tree-ring sampling}

Three sampling sites along an altitudinal gradient were established in September 2008 (Fig. 1). The low elevation site (LowE), DFL, was in the Red-East Forest Farm on the northern slopes of the Changbai Mountains; the mid- and high-elevation sites (MidE and HighE), DXS and CBB, were on the northern slopes in the Changbai Mountains 


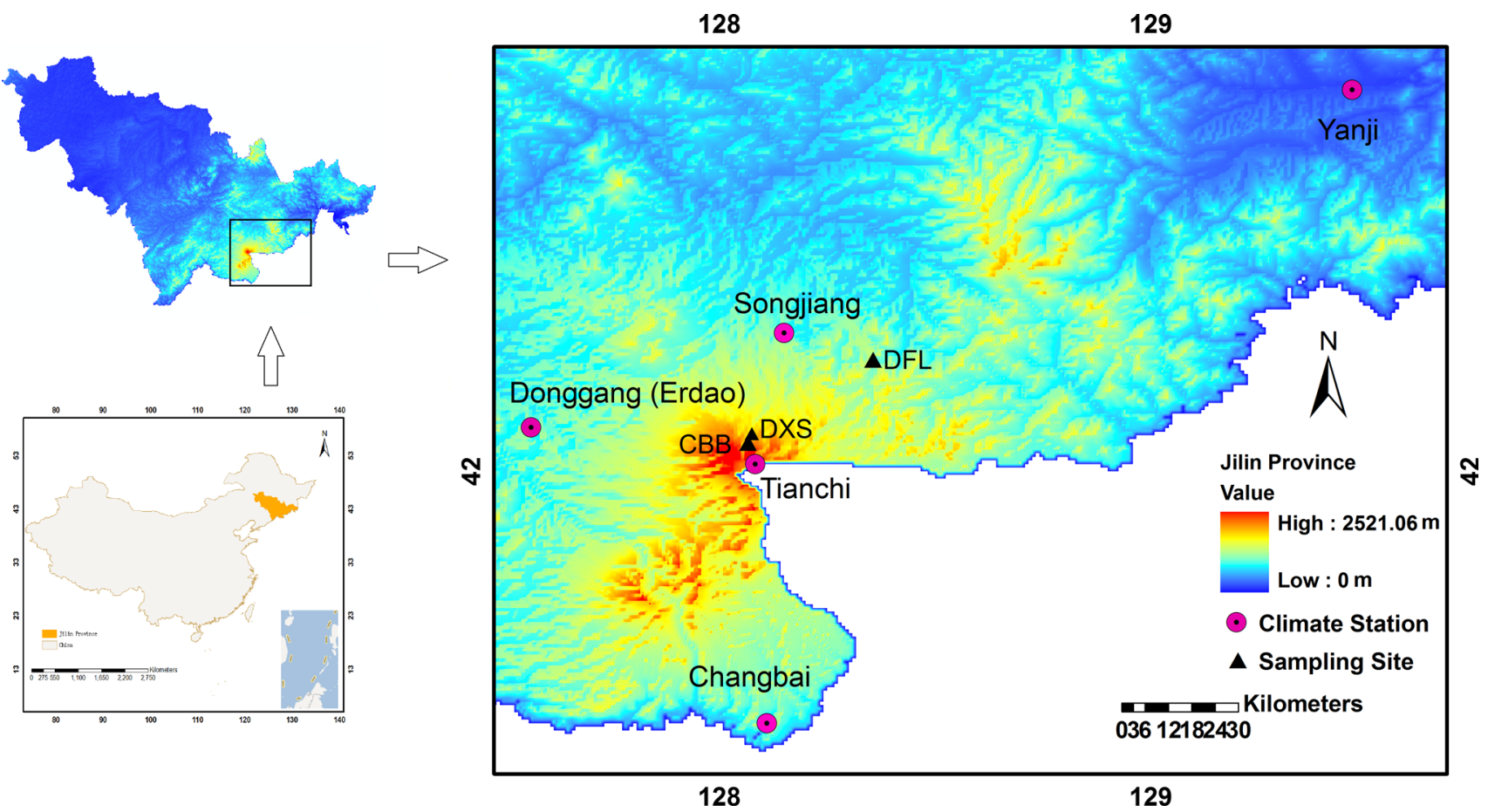

Fig. 1 Map of the study areas showing locations of climate stations and sampling sites

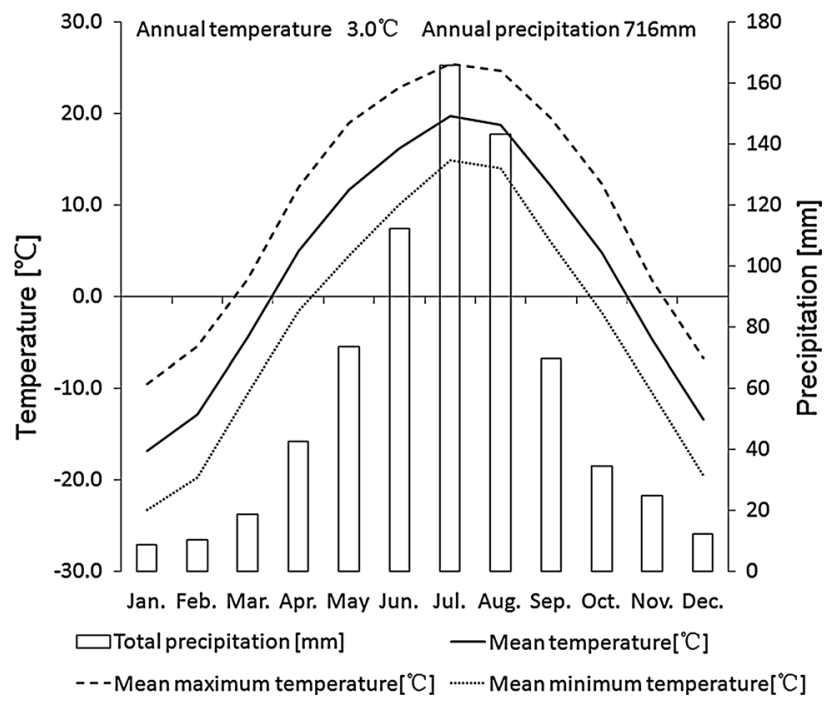

Fig. 2 Monthly mean temperature, mean maximum and minimum temperatures and monthly precipitation in the study area from 1958 to 2008

Natural Reserve. The elevation of each sampling site was within the elevation range of each forest type, which could reflect the vertical distribution limit of Changbai larch and capture its growth under different conditions. At each site, we selected at least 20 trees with the largest canopies (normally old) and with no visible injuries or cracks in the bark for tree core sampling. Two cores (plus a third one held in reserve in case one of the former two was unusable) taken $90^{\circ}$ apart (from directions perpendicular and parallel to the slope) were extracted from each sampling tree at the breast height using an increment borer. Among all three sites, 135 cores were obtained from 66 living Changbai larch trees (Table 1).

\section{Ring width and density measurements}

Each core was numbered, air dried and sanded. Then, tree rings were visually dated using a binocular microscope (Nikon Corporation, Tokyo, Japan). Tree-ring widths were measured to the nearest $0.01 \mathrm{~mm}$ using a LINTAB 6 professional width measuring device (Frank Rinn, Heidelberg, Germany). The COFECHA program (Holmes 1983, 1992) was run to verify the visual dating (Fritts 1976; Cook et al. 1990). Density was measured using a Dendro 2003 system (Walesch Electronics, Effretikon, Switzerland). Each core was separated into pieces with approximately equal lengths. The wood fiber angles of those pieces were measured and calibrated using a fiber angle measuring instrument Dendroscope. All cores were cut into 1.0-mm thick slices with a technical twin-blade cutting device Dendrocut with the direction in the plane perpendicular to the corresponding wood fiber angles. Normally, resins should be extracted with a Soxhlet extractor in ethanol or acetone. Schweingruber (1988) reported that the heartwood substances (like resin and carbohydrate) of several species, like Larix, Tsuga and Fitzroya, are water soluble. In 
Table 1 Information about sampling sites on the northern slopes of the Changbai mountains area

\begin{tabular}{llllllll}
\hline Site name & Site code & Elevation $(\mathrm{m})$ & Latitude & Longitude & Cores (trees) & Slope & Aspect \\
\hline DFL & LowE & 983 & $42^{\circ} 15^{\prime} 27.4^{\prime \prime} \mathrm{N}$ & $128^{\circ} 21^{\prime} 22.8^{\prime \prime} \mathrm{E}$ & $42(20)$ & $0^{\circ}$ & 0 \\
DXS & MidE & 1585 & $42^{\circ} 05^{\prime} 13.6^{\prime \prime} \mathrm{N}$ & $128^{\circ} 04^{\prime} 29.9^{\prime \prime} \mathrm{E}$ & $41(20)$ & $5^{\circ}$ & $\mathrm{NW}$ \\
$\mathrm{CBB}$ & HighE & 1848 & $42^{\circ} 03^{\prime} 54.5^{\prime \prime} \mathrm{N}$ & $128^{\circ} 04^{\prime} 00.3^{\prime \prime} \mathrm{E}$ & $52(26)$ & $25^{\circ}$ & $\mathrm{NW}$ \\
\hline
\end{tabular}

addition, other researchers reported that the water-soluble fraction of extractives is much higher than organic-solvent fraction for larch species (Gierlinger et al. 2004). Consequently, resin in the wood was extracted by soaking these slices with pure water at $80{ }^{\circ} \mathrm{C}$ for $48 \mathrm{~h}$. Tree-ring density was determined by $\mathrm{X}$-ray densitometry. The values of seven parameters were measured and calculated simultaneously for each ring, including earlywood width (EWW), latewood width (LWW), total ring width (TRW), earlywood mean densitiy (EMD), earlywood minimum density (MID), latewood mean density (LMD) and latewood maximum density (MXD). The COFECHA program (Holmes 1983, 1992) was adopted for density crossdating.

\section{Chronology development}

Radial growth chronologies of Changbai larch were developed by crossdating tree-ring growth series using the ARSTAN program (Cook 1985; Cook and Holmes 1996). These growth series were detrended by fitting a cubic smooth spline with $67 \%$ of the series length to remove the biological growth trends associated with tree age (Cook et al. 1990). Points from the fitted curves were then divided by actual growth parameter values to generate standardized index series. The index series were averaged by a bi-weight robust mean to compute mean standardized chronologies (STD). The standardized chronologies were then pre-whitened via autoregressive modeling to produce residual chronologies (RES). The expressed population signal value (EPS), defined by the proportion of each chronology signal in the total chronology variance, was used to quantify the extent of the reliability of a particular chronology (Wigley et al. 1984; Briffa and Jones 1990). Since residual chronologies were less affected by abnormal fluctuations of tree rings over long periods, we used residual chronologies in this study.

\section{The climate-tree-ring growth relationships}

The relationships between climate and tree-ring parameters during the period 1958-2008 were investigated via Pearson's correlation analysis using SPSS 17.0. The climate variables were monthly mean temperature (MT), mean maximum temperature (MAXT), mean minimum temperature (MINT) and monthly precipitation (MP). To avoid the effect of inter-correlation between temperature and precipitation, we calculated partial correlation between the residual chronologies and climatic variables. The analysis spanned from September of the previous year to September of the current year (a total of 13 months); and the current spring (March to May), summer (June to August) and the growing season (April to September) were analyzed separately. In conifer species, tree-ring density is related to the ratio of tracheid cell-wall thickness to cell lumen diameter within an annual ring (Vaganov 1990; Wang et al. 2002). Hence, only correlations between tree-ring density and climate variables during the current year were considered.

Annual climate data from 1958 to 2008 were analyzed to identify trends of temperature and precipitation during these five decades (Fig. 3). Overall, the annual mean temperature rose whereas the annual precipitation decreased in this period. The annual mean temperature began to rise abruptly around 1989. For this study, the relationships between monthly mean temperature and the residual chronologies within two consecutive phases

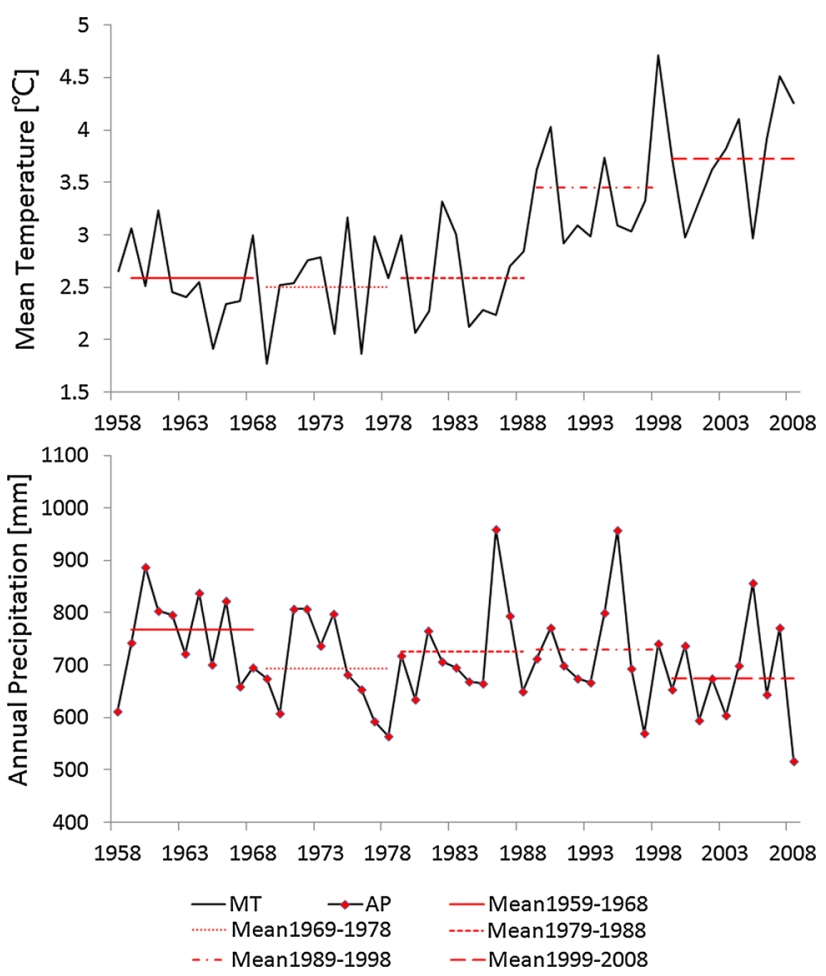

Fig. 3 Trends of annual mean temperature and annual precipitation in the study area from 1958 to 2008 . A red line represents the average value within one decade 
(Phase I, 1959-1988; Phase II, 1989-2008) were examined to determine the temporal stability of the climate-growth relationships under warming. To start off, a null hypothesis was proposed that the correlations of climate-growth relationship from the two periods were equal. "Fisher transformation" was applied to test the climate-growth correlation coefficients from the two phases (Fisher 1915). All probability values of the sample mean failed to approach the level of significance (at 0.05 level), which indicates that the null hypothesis should be rejected. Hence, temporal instability of the climate-tree growth relationships appears real and important to analyze further.

\section{Results}

\section{Chronology characteristics}

Figures 4 and 5 show the residual chronologies of TRW and MXD along the altitudinal gradient. The chronologies of LowE site were much longer than those at the other two elevations. TRW chronology curves showed higher interannual variations than MXD. The inter-annual variability of MXD increased with ascending elevation.

Table 2 displays descriptive statistics of the chronologies. The mean sensitivity (MS) and standard deviation (STD) values of TRW chronologies were highest at HighE site and lowest at LowE site. The same results emerged for the correlations "among all radii" (RAR) and "between trees" (RBT) of TRW chronologies, which implies that the annual growth similarities among trees increase along elevation. The inconsistent tendency of the "within trees"
(RWT) correlation coefficients reflects the complexity of tree growth at all sampling points along the altitudinal gradient. Signal-to-noise ratio (SNR) values were all high and increased with elevation, showing that TRW at higher elevations responds more strongly to environmental parameters. In particular, EPS values exceeding the benchmark 0.85 (especially EPS $>0.90$ ) indicates the theoretical population for all chronologies is well represented at each site. The high values of the first principal component (PC1) suggest that the chronologies could explain a great amount of the variance of TRW. All statistical variable values increased with elevation for MXD chronologies, which implies that MXD responds significantly to environmental factors at all elevations, especially at higher elevations.

\section{Climate-tree-ring growth relationships}

Tree-ring growth responses to climate parameters varied with the elevation of sampling sites. Significant negative correlations were found between TRW and monthly temperatures in February as well as MAXT in previous September at LowE site (Fig. 6). At MidE site, TRW responded negatively to monthly temperatures in previous winter while positively to MT and MAXT in current May. TRW was significantly negatively related to monthly temperatures in current March, April and spring at HighE site. Significant positive correlation was also found between TRW and MAXT in current June at HighE site.

TRW was seen positively associated with MP in previous September, current April, summer and the growing season at LowE site. TRW corresponded negatively to MP in previous December and current September at MidE site.
Fig. 4 Residual chronologies of TRW along the altitudinal gradient. The arrow indicates the starting year of SSS (subsample signal strength) $>0.85$

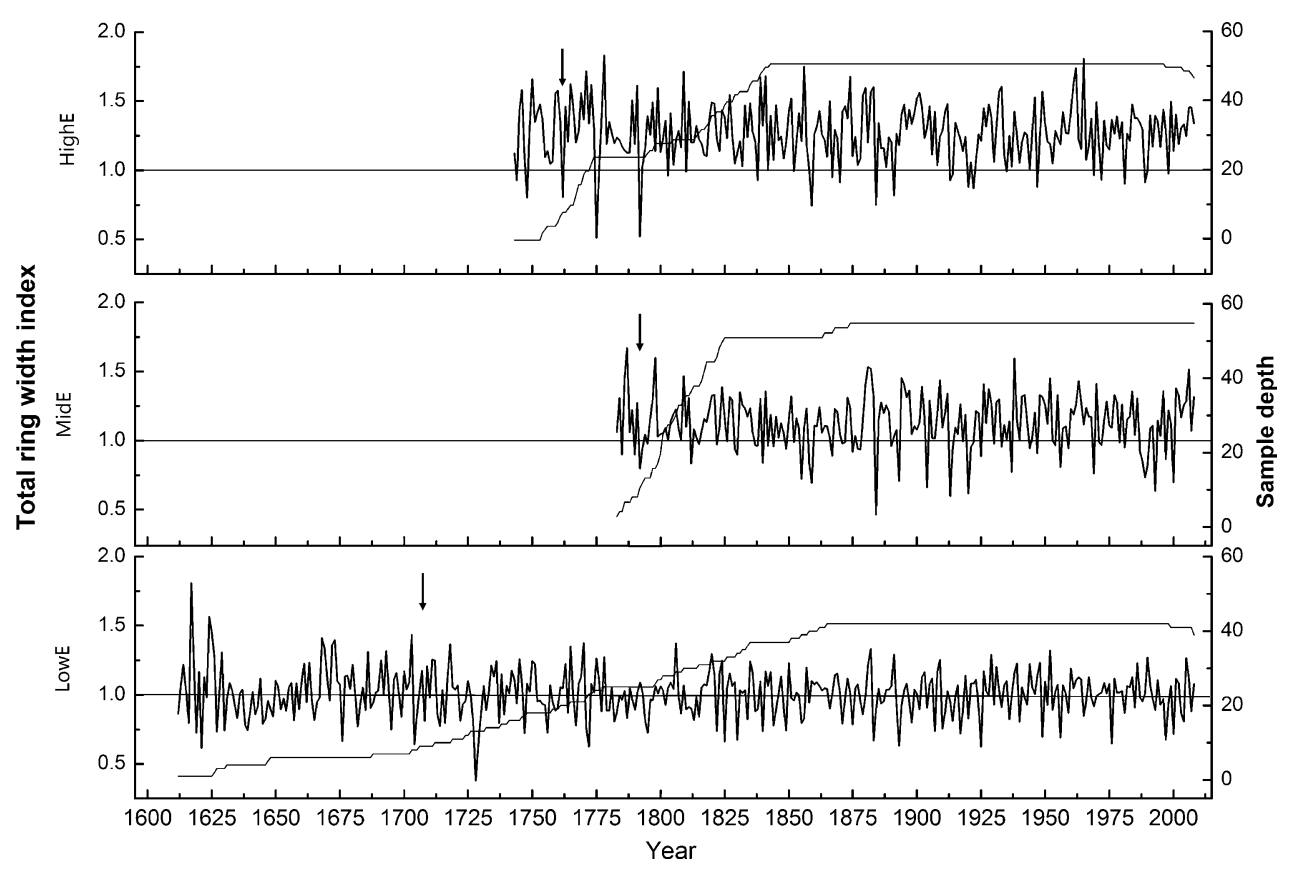


Fig. 5 Residual chronologies of MXD along the altitudinal gradient. The arrow indicates the starting year of SSS (subsample signal strength) $>0.85$ "

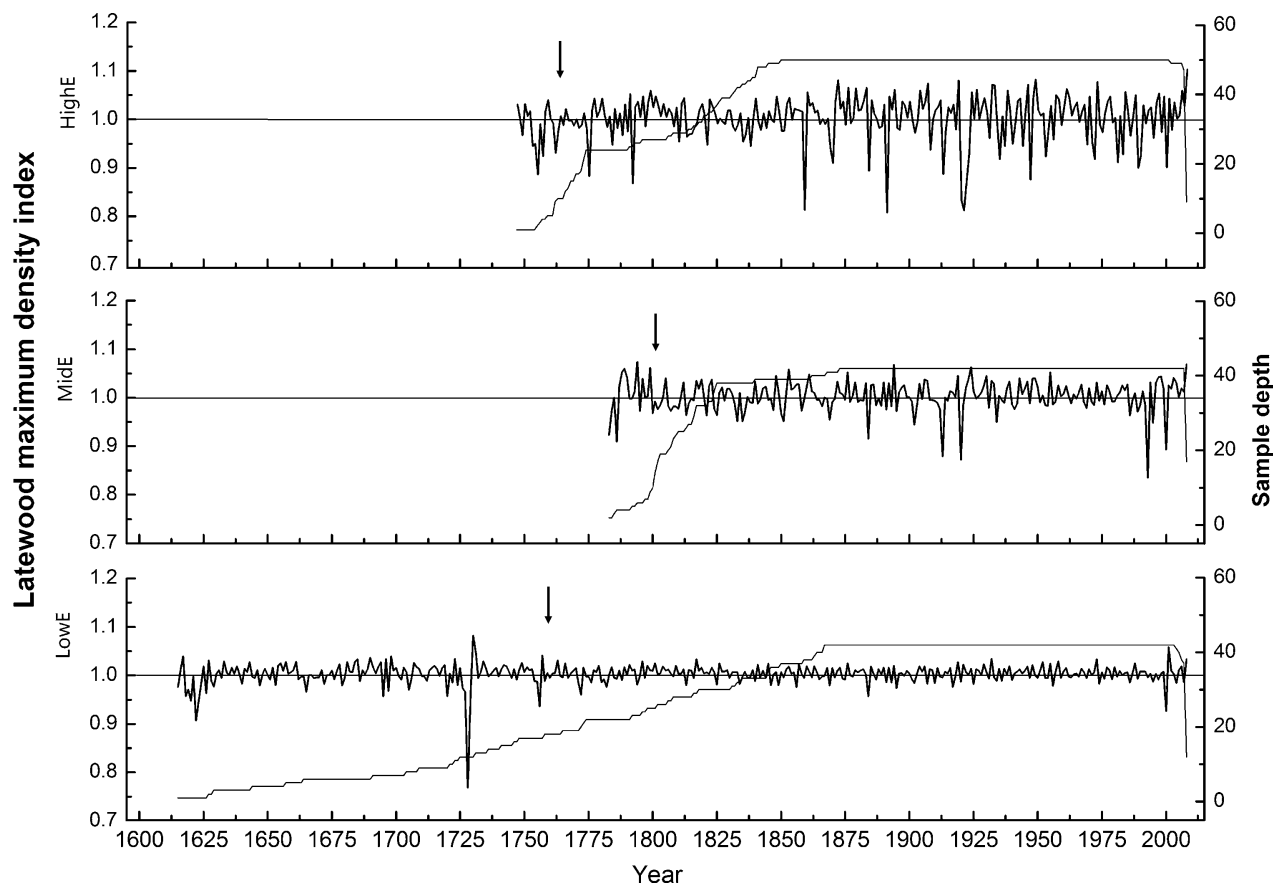

Table 2 The chronology and common interval statistics of tree-ring growth indices at three elevations on the northern slopes of the Changbai mountains area

\begin{tabular}{|c|c|c|c|c|c|c|c|c|c|c|c|c|}
\hline $\begin{array}{l}\text { Residual } \\
\text { chronology }\end{array}$ & $\begin{array}{l}\text { Sample } \\
\text { sites }\end{array}$ & $\begin{array}{l}\text { Starting } \\
\text { year }\end{array}$ & $\begin{array}{l}\text { Common } \\
\text { interval }\end{array}$ & MS & STD & RAR & RWT & RBT & SNR & $\begin{array}{l}\mathrm{SSS} \geq 0.85 \\
\text { starting year }\end{array}$ & EPS & $\begin{array}{l}\mathrm{PC} 1 \\
(\%)\end{array}$ \\
\hline \multirow[t]{3}{*}{ TRW } & LowE & 1612 & 1866-2000 & 0.198 & 0.171 & 0.351 & 0.670 & 0.341 & 22.141 & 1706 & 0.957 & 37.4 \\
\hline & MidE & 1783 & 1876-2000 & 0.163 & 0.193 & 0.392 & 0.623 & 0.386 & 26.422 & 1792 & 0.964 & 41.3 \\
\hline & HighE & 1743 & $1841-2000$ & 0.264 & 0.215 & 0.489 & 0.623 & 0.487 & 47.906 & 1761 & 0.980 & 50.3 \\
\hline \multirow[t]{3}{*}{ MXD } & LowE & 1615 & $1871-2000$ & 0.019 & 0.022 & 0.124 & 0.395 & 0.115 & 5.918 & 1765 & 0.855 & 16.0 \\
\hline & MidE & 1783 & 1876-2000 & 0.036 & 0.033 & 0.289 & 0.450 & 0.285 & 17.051 & 1801 & 0.945 & 32.3 \\
\hline & HighE & 1747 & $1851-2000$ & 0.053 & 0.048 & 0.417 & 0.558 & 0.414 & 35.740 & 1762 & 0.973 & 43.7 \\
\hline
\end{tabular}

$M S$ Mean sensitivity, STD standard deviation, $R A R$ mean correlation among all radii, $R W T$ correlation within trees, $R B T$ correlation between trees, $S N R$ signal to noise ratio, SSS subsample signal strength, EPS expressed population signal, $P C 1$ variance for the first principal component

And at HighE site, TRW was negatively corresponded to MP in current June while positively correlated to MP in current August. Partial correlation analysis indicates that the effect of MP in prior September on TRW is very weak when MAXT in prior September was controlled at LowE site. The same results were found for the effects of prior December precipitation and June precipitation on TRW at MidE and HighE sites, respectively.

The relationships between MXD and monthly variables are displayed in Fig. 7. At MidE site, MXD was positively associated with temperatures in April, MT and MAXT in summer even the entire growing season, and MAXT in August and September. MXD was also positively correlated with MT and MAXT in summer at HighE site.

While MXD was negatively correlated with January precipitation at LowE site, it was negatively correlated with precipitation in June and the growing season at both MidE and HighE sites. Partial correlation analysis suggests that MAXT affected MXD more significantly than MP during summer at higher elevation sites.

The temporal instability of the climate-tree-ring growth relationships was investigated by examining the correlations between the residual chronologies and monthly mean temperature (MT) during the two consecutive spans (phase I, 1959-1988; phase II, 1989-2008) (Fig. 8). Obvious instability was present in the relationships between treering parameters and MT from phase I to phase II. During phase I, TRW was mainly negatively associated with MT in February at both LowE and MidE sites, and MT in April and spring at HighE site. By contrast, TRW was only negatively correlated with MT in June at LowE site during phase II. Significantly positive correlations were found 
Fig. 6 Correlation coefficients between TRW chronologies and monthly climatic variables for Changbai larch along the altitudinal gradient $(p<0.05)$

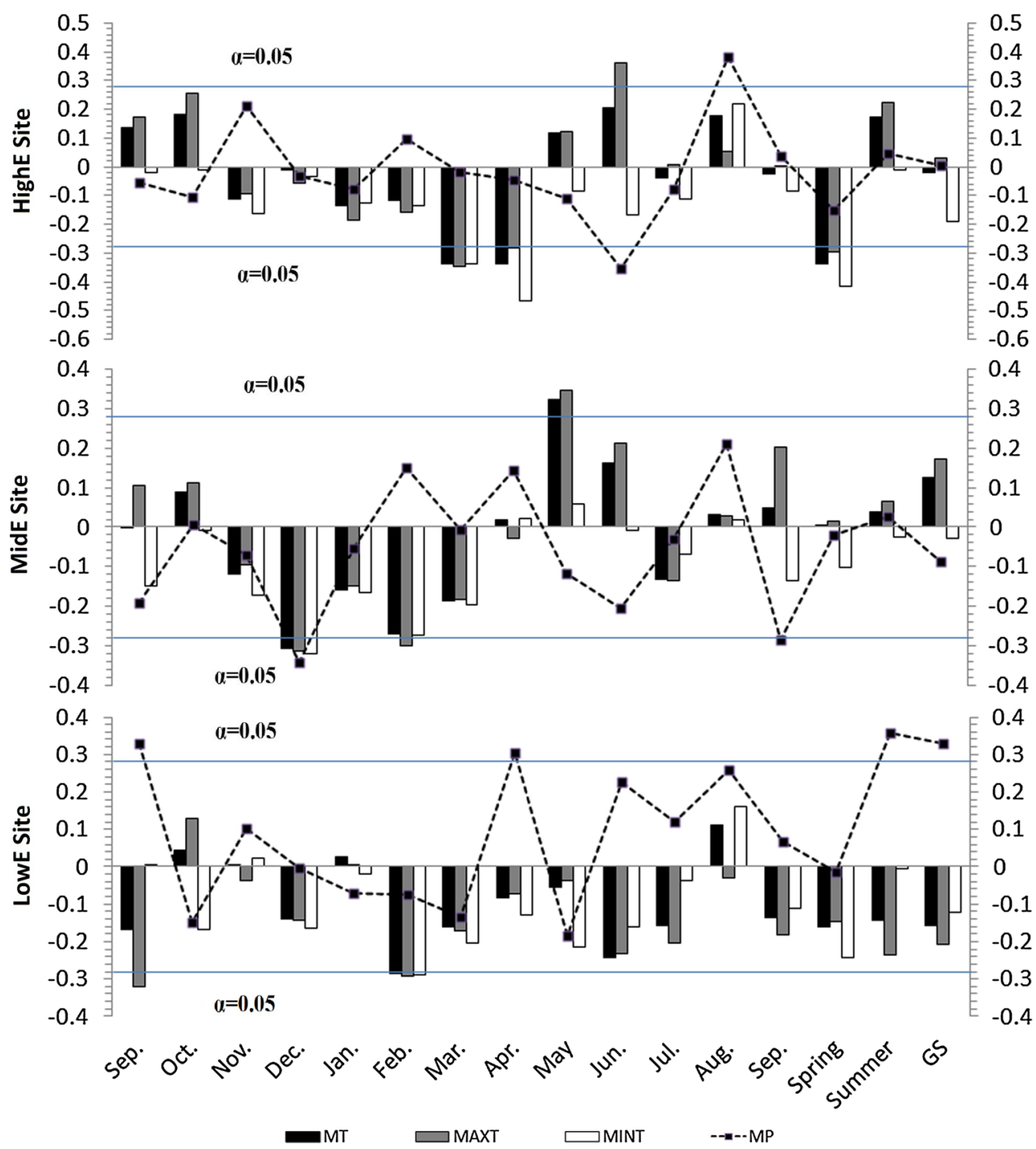

between growth and climate at higher elevation sites, such as MT in June, September, and the growing season at MidE site and MT in June and summer at HighE site during phase II. MXD significantly positively corresponded to mean temperatures at all sites along the altitudinal gradient in phase I, while MXD only remained sensitive to rising temperature during phase II, especially MT in summer and the growing season at MidE site.

\section{Discussion}

\section{Chronology evaluation}

Our results suggest that tree-ring analysis provides a very useful method for exploring the relationships between climate change and tree-ring width growth, which is in line with previous studies of different tree species conducted in the Changbai Mountains area (Shao and Wu 1997; Chen et al. 2011; Sun 2011; Yu et al. 2013). Statistical analysis showed quite high quality for the residual chronologies (Table 2). The increases in RAR, RBT, EPS and PC1 values with elevation indicate that response to climate is stronger at higher elevations for TRW and MXD. The different RWT values of TRW chronologies imply that tree-ring width of current year is related differently to climate in previous years.

In our study, MS and STD values of TRW chronologies were rather high compared with other species, which is consistent with previous studies involving Changbai larch (Chen et al. 2011; $\mathrm{Li}$ et al. 2011). MS values varied with elevation, which suggests that tree-ring growth responds differently to climate variables along the altitudinal gradient. 
Fig. 7 Correlation coefficients between MXD chronologies and monthly climatic variables for Changbai larch along the altitudinal gradient $(p<0.05)$

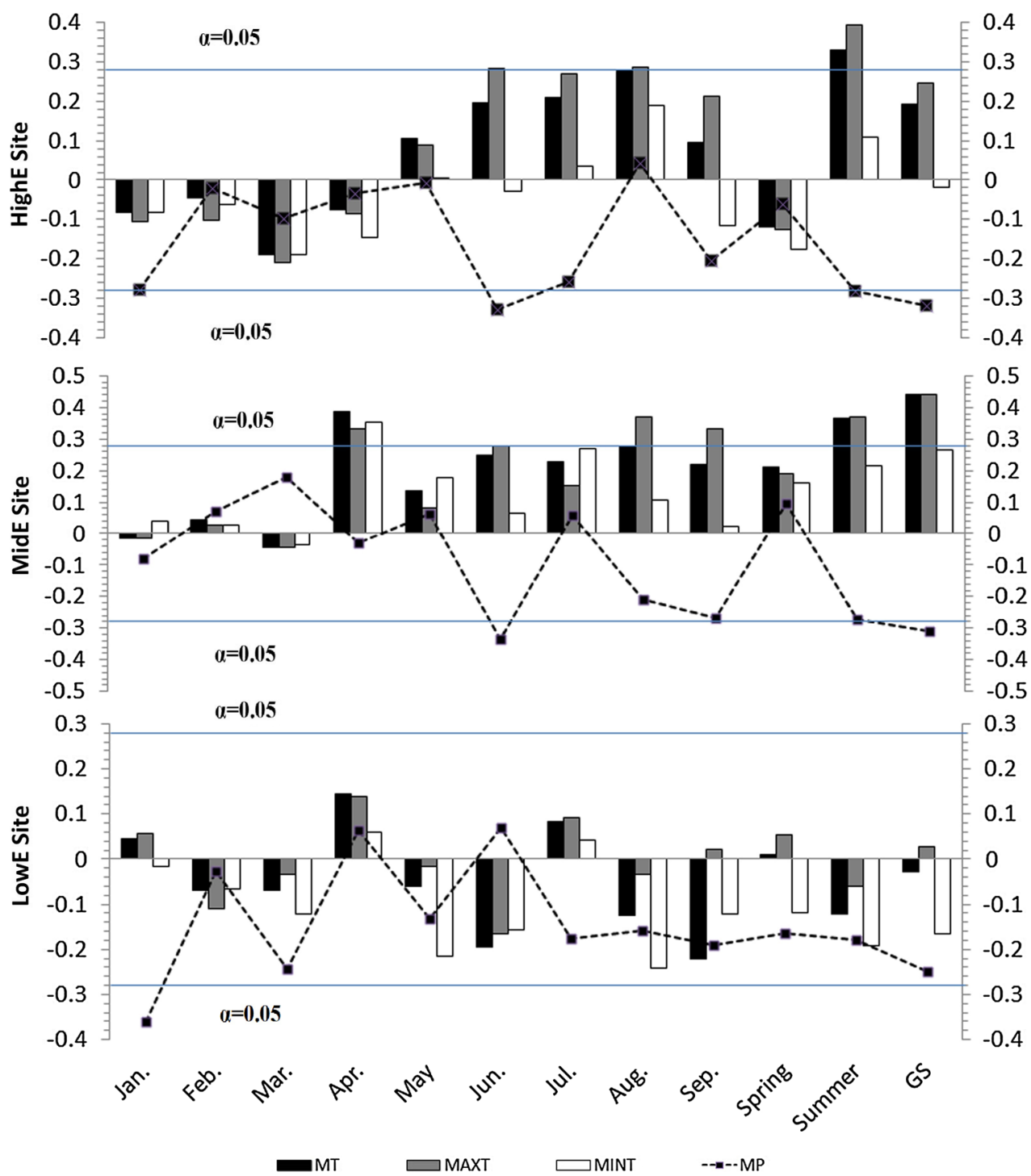

photosynthates would be consumed from storage (Pilcher and Gray 1982; Shao and Wu 1997).

In contrast, there were positive correlations between tree growth and temperature in the prior winter reported for other areas or tree species (Pederson et al. 2004; Liang et al. 2010). The differences might result from inherent diversity of growth patterns among tree species and specific climatic conditions. TRW was found positively correlated to MT and MAXT in current May and June at MidE and HighE sites. Similar relationships were reported by $\mathrm{Yu}$ et al. (2005) for Changbai larch growing at high elevation. In the Changbai Mountains area, May and June already signal late spring and early summer. With rising temperature, enhanced photosynthesis stimulates and accelerates the expansion growth of cambium cells after division, which in turn increases tree-ring width. 
Fig. 8 Variability of correlation coefficients between tree-ring chronologies and monthly mean temperature for Changbai larch during the phases of 1959-1988 and 1989-2008. The solid circles and open circles represent positive and negative correlations, respectively. The size of the circle symbolizes the strength of the correlation. The gray shading stands for a significant correlation at the 0.05 level (2-tailed test). Circles without shading suggest insignificant correlations

\begin{tabular}{|c|c|c|c|c|c|c|c|c|c|c|c|c|c|c|}
\hline & Site & Phase & Jan & Feb & Ma & Ap & Ma & Jun & Jul & Aug̨ & Sep & Spr & Sun & GS \\
\hline \multirow{6}{*}{ TRW } & \multirow{2}{*}{ LowE } & 1959-1988 & $\cdot$ & 0 & 。 & - & - & $\bullet$ & & - & . & & - & $\bullet$ \\
\hline & & $1989-2008$ & - & & & 。 & o & 0 & $\circ$ & & 。 & $\circ$ & 0 & 0 \\
\hline & \multirow{2}{*}{ MidE } & $1959-1988$ & o & 0 & 。 & . & 0 & $\bullet$ & 0 & $\cdot$ & o & . & $\cdot$ & • \\
\hline & & 1989-2008 & . & & & - & $\bullet$ & 0 & . & . & 0 & • & $\bullet$ & O \\
\hline & \multirow{2}{*}{ HighE } & 1959-1988 & $\circ$ & & o & 0 & • & $\bullet$ & $\circ$ & • & 。 & 0 & $\bullet$ & 。 \\
\hline & & $1989-2008$ & . & $\circ$ & 0 & 。 & . & 0 & $\bullet$ & - & - & 0 & 0 & - \\
\hline \multirow{6}{*}{ MXD } & \multirow{2}{*}{ LowE } & 1959-1988 & $\bullet$ & 。 & 。 & • & 。 & $\bullet$ & 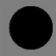 & • & $\bullet$ & & & 0 \\
\hline & & $1989-2008$ & - & - & - & - & & 0 & $\circ$ & 0 & 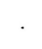 & - & 0 & 。 \\
\hline & \multirow{2}{*}{ MidE } & $1959-1988$ & 。 & · & $\circ$ & • & 0 & . & - & 0 & $\bullet$ & - & 0 & \\
\hline & & $1989-2008$ & . & • & . & 0 & . & 0 & - & $\bullet$ & $\bullet$ & - & 0 & 0 \\
\hline & \multirow{2}{*}{ HighE } & 1959-1988 & 。 & & o & 0 & $\bullet$ & - & - & 0 & & o & 0 & • \\
\hline & & $1989-2008$ & . & 。 & $\circ$ & • & . & $\bullet$ & - & • & $\bullet$ & & $\bullet$ & - \\
\hline
\end{tabular}

Although annual rainfall is abundant in the Changbai Mountains area, monthly precipitation still impacts significantly on TRW at three altitudes. Previous studies had reported that tree growth is not limited by water stress in this area (Wang and Tao 1998). Furthermore, adequate precipitation is a positive factor to tree growth in this area. At LowE site, precipitation during the growing season contributes to TRW because ample rainfall ensures soil moisture for growth. This positive effect was also found for August precipitation on TRW at HighE site. In addition, TRW was negatively associated with an excess of precipitation rather than precipitation shortage. At HighE site, excessive precipitation in current June (the peak of the growing season) would lead to higher air humidity, lower temperature and waterlogging in soil, which would seriously reduce oxygen content, and restrict respiration and transpiration of trees. However, the partial correlation analysis suggests that TRW is still mainly controlled by temperature in current June.

At the end of the growing season, temperature drops significantly and respiration decreases leading to suspension of tree growth. During that span, the photosynthetic production provides photosynthates for the thickening of the secondary xylem rather than the enlargement of latewood cells. This suggests that the negative correlation between tree-ring width and precipitation in September might lose biological significance. This phenomenon was also reported for Dahurian larch (Larix gmelini) in Great Khingan Mountains area in northeast of China (Wang et al. 2005).

In contrast to TRW, MXD was positively affected by temperatures while negatively influenced by precipitation
(Fig. 7). MXD was correlated with temperatures during the growing season (especially in summer months) at both MidE and HighE sites. With rising temperature in the growing season, suitable thermal conditions would stimulate the division and enlargement of xylem cells, to be thickened later when photosynthates could be exclusively directed to latewood cells of Changbai larch. Our findings are consistent with the results of Dahurian larch reported by Wang et al. (2005).

January precipitation negatively impacted on MXD at LowE site. The mechanism whereby January precipitation influences MXD is not clear. In January, snow and rainfall would reduce temperature, which is already very low in winter. Phenological research suggests that winter temperatures would control the starting time of vegetation growth in the following spring (Zhu and Wan 1999). If start of the growing season is delayed, xylem cells may not have sufficient time to fully thicken during the remaining growing season.

\section{The temporal instability of the climate-tree-ring growth relationships}

Rising temperature in late 1980s in northeastern region is in agreement with previous studies related to climate change in China (Ding et al. 2006; Zhao and Luo 2007). Warming in the area has resulted in the temporal instability of the climate-tree-ring growth relationships for Changbai larch along the altitudinal gradient. First, the response of TRW to warming varied markedly with altitude. At lowelevation areas, tree-ring growth was subject to drought 
stress caused by increasing temperature in June. Actually, the environment of low elevation areas was complex, especially with human disturbances such as cutting or thinning for timber by foresters. The effects of rising temperature might diminish when the forest density was reduced. The increasing sensitivity of TRW at middle and high elevations to rising temperature was obvious, and in accordance with the positive response to temperature in summer and the entire growing season in the period of 1959-2008. It is the reason that abundant precipitation at higher areas provided relatively moist conditions to ease the probable drought stress caused by increasing temperature. The finding that tree-ring width increased with warming at higher elevations could support the proposed relationship between rising temperature and tree growth in northeastern China observed in previous studies ( $\mathrm{He}$ et al. 2005; Chen and Yan 2008).

The MXD response to warming in the 1980s varied with elevation. MXD tended to lose sensitivity to increasing temperature at low and high elevations while maintaining a positive relationship with MT at middle elevation. The result indicates that temperature was influential on tree-ring density after the late 1980s at low and high elevations. This situation might be related to tree age structure difference at three elevations. Trees growing at middle elevation were generally younger than those at low and high elevations (Table 2). Temporal instability in climate-tree-ring growth relationships was also found to affect the reconstruction of past climates (Wilson and Elling 2004). Our result implies that temporal instability should be accounted for to improve the reliability of reconstruction for past climates.

\section{Conclusions}

Both temperature and precipitation significantly affect treering growth of Changbai larch (Larix olgensis Henry) in the Changbai Mountains area, northeast of China. By comparing the impacts of climatic variables on tree-ring width and density along an altitudinal gradient, we find that the treering width and density respond differently to climate change. Our results indicate that temperature is the dominant influence on the width of annual rings for Changbai larch, and precipitation also seems to affect tree-ring growth indirectly by reducing temperature. The effect is complex, i.e., sometimes negative in the previous winter at lower elevations while positive during the growing season at higher elevations. Latewood maximum density of Changbai larch responds positively to temperature along the altitudinal gradient. In contrast, precipitation mainly limits latewood maximum density. The temporal instability of tree-ring growth response to temperature occurred due to abrupt warming in the late 1980s. Tree-ring width responds less severely to drought stress after warming at low elevation while it shows more sensitivity to rising temperature at middle and high elevations. Temperature gradually ceases to influence latewood maximum density after the warming at low and high elevations; while the density responds to rising temperature consistently in the two spans (1959-1988, 1989-2008) at middle elevation. Our study could improve understanding of tree-ring growth sensitivity corresponding to climate change especially warming along an altitudinal gradient. Therefore, the findings could assist in research on reconstruction of past climates, the variability of tree-ring growth and forest distribution under climate change.

Author contribution statement Dr. Chenchen Shen is responsible for designing study procedure, measuring and analyzing data, and writing and revising the manuscript. Dr. Lily Wang is the advisor of the other authors. She guided the first author on research planning, tree-ring experiments and revising the manuscript. Dr. Mingyong Li assisted in the experiments and provided great advice for the manuscript.

Acknowledgments This work was supported by the National Science Foundation of China (41271120) and the Open Fund of the State Key Laboratory of Loess and Quaternary Geology (SKLLQG1320), Institute of Earth Environment, Chinese Academy of Sciences. We thank the China Meteorological Data Sharing Service System for sharing the climatic data, Dr. Yu Sun for his assistance with the sample collection, and the two anonymous reviewers and editors for their valuable review comments that helped greatly to improve our manuscript.

\section{Compliance with ethical standards}

Conflict of interest The authors declare that they have no conflict of interest

\section{References}

Alexandersson H, Moberg A (1997) Homogenization of Swedish temperature data. Part I: homogeneity test for linear trends. Int J Climatol 17:25-34

Allen CD, Macalady AK, Chenchouni H, Bachelet D, McDowell N, Vennetier M, Kitzberger T, Rigling A, Breshears DD, Hogg E (2010) A global overview of drought and heat-induced tree mortality reveals emerging climate change risks for forests. For Ecol Manag 259(4):660-684. doi:10.1016/j.foreco.2009.09.001

Anderegg WR, Kane JM, Anderegg LD (2013) Consequences of widespread tree mortality triggered by drought and temperature stress. Nat Clim Chang 3:30-36. doi:10.1038/nclimate1635

Biondi F (2000) Are climate-tree growth relationships changing in north-central Idaho, USA? Arct Antarct Alp Res 32:111-116

Bräuning A (1999) Dendroclimatological potential of drought-sensitive tree stands in southern Tibet for the reconstruction of monsoonal activity. IAWA J 20:325-338

Briffa KR, Jones PD (1990) Basic chronology statistics and assessment. In: Cook ER, Kairiukstis LA (eds) Methods of dendrochronology: applications in the environmental sciences. Kluwer Academic Publishers, Boston, pp 137-152

Chen XX, Yan XD (2008) Effects of climate change on typical forest in the northeast of China. Acta Ecol Sin 28:534-543 (in Chinese with English abstract) 
Chen L, Wu SH, Pan T (2011) Variability of climate-growth relationships along an elevation gradient in the Changbai mountains, northeast China. Trees 25:1133-1139. doi:10.1007/ s00468-011-0588-0

Cook ER (1985) A time-series approach to tree-ring standardization. $\mathrm{Ph} . \mathrm{D}$ thesis, University of Arizona, Tucson, Arizona

Cook ER, Holmes RL (1996) Guide for computer program ARSTAN. In: Grissino-Mayer HD, Holmes RL, Fritts HC (eds) The international tree-ring data bank program library version 2.0 user's manual. University of Arizona, Tucson, Arizona

Cook ER, Briffa KR, Shiyatov S, Mazepa V (1990) Tree-ring standardization and growth-trend estimation. In: Cook ER, Kairiukstis LA (eds) Methods of dendrochronology: applications in the environmental sciences. Kluwer Academic Publishers, Boston, pp 104-122

D'Arrigo RD, Wilson R, Liepert B, Cherubini P (2007) On the 'divergence problem' in northern forests: a review of the treering evidence and possible causes. Global Planet Change 60(3-4):289-305. doi:10.1016/j.gloplacha.2007.03.004

Ding YH, Ren GY, Shi GY, Gong P, Zheng XH, Zhai PM, Zhang DE, Zhao ZC, Wang SW, Wang HJ (2006) National Assessment Report of Climate Change (I): climate change in China and its future trend. Adv Clim Chang Res 2(1):3-8

Dittmar C, Zech W, Elling W (2003) Growth variation of common beech (Fagus sylvatica L.) under different climatic and environmental conditions in Europe-a dendroecological study. For Ecol Manag 173:63-78. doi:10.1016/s0378-1127(01)00816-7

Driscoll WW, Wiles GC, D'Arrigo RD, Wilmking M (2005) Divergent tree growth response to recent climatic warming, Lake Clark National Park and Preserve, Alaska. Geogr Res Lett 32(20):L20703. doi:10.1029/2005GL024258

Fisher RA (1915) Frequency distribution of the values of the correlation coefficient in samples of an indefinitely large population. Biometrika 10(4):507-521. doi:10.2307/2331838

Fritts HC (1976) Tree rings and climate. Academic Press, London, p 23

Gierlinger N, Jacques D, Schwanniger M, Wimmer R, Pâques (2004) Heartwood extractives and lignin content of different larch species (Larix sp.) and relationships to brown-rot decayresistance. Trees 18:230-236. doi:10.1007/s00468-003-0300-0

Hao ZQ, Dai LM, He HS, Malandnoff DJ, Shao GF (2001) Potential response of major tree species to climate warming in Changbai Mountains, northeast China. Chin J Appl Ecol 12(5):652-658 (in Chinese with English abstract)

He HS, Hao ZQ, Mladenoff DJ, Shao GF, Hu YM, Chang Y (2005) Simulating forest ecosystem response to climate warming incorporating spatial effects in north-eastern China. J Biogeogr 32(12):2043-2056. doi:10.1111/j.1365-2699.2005.01353.x

Holmes RL (1983) Computer-assisted quality control in tree-ring dating and measurement. Tree-Ring Bull 43:69-78

Holmes RL (1992) Dendrochronology Program Library, Version 1992-1. Laboratory of Tree-Ring Research, University of Arizona, Tucson, ArizonaLi GQ, Bai F, Sang WG (2011) Different responses of radial growth to climate warming limits in Pinus koraiensis and Picea jezoensis var. komarovii at their upper elevational limits in Changbai Mountains, China. Chin J Plant Ecol 35:500-511 (in Chinese with English abstract)

Li GQ, Bai F, Sang WG (2011) Different responses of radial growth to climate warming limits in Pinus koraiensis and Picea jezoensis var. komarovii at their upper elevational limits in Changbai Mountains, China. Chin J Plant Ecol 35:500-511 (in Chinese with English abstract)

Liang EY, Wang YF, Xu Y, Liu B, Shao XM (2010) Growth variation in Abies georgei var. smithii along altitudinal gradients in the Sygera Mountains, southeastern Tibetan Plateau. Trees 24:363-373. doi:10.1007/s00468-009-0406-0
Lloyd AH, Fastie CL (2002) Spatial and temporal variability in the growth and climate response to treeline trees in Alaska. Clim Chang 52(4):481-509. doi:10.1023/a:1014278819094

Magnin A, Puntieri J, Villalba R (2014) Interannual variations in primary and secondary growth of Nothofagus pumilio and their relationships with climate. Trees 28:1463-1471. doi:10.1007/ s00468-014-1049-3

Mérian P, Bontemps JD, Bergés L, Lebourgeois F (2011) Spatial variation and temporal instability in climate-growth relationships of sessile oak (Quercus petraea [Matt.] Liebl.) under temperate conditions. Plant Ecol 212(11):1855-1871. doi:10. 1007/s11258-011-9959-2

Pederson N, Cook ER, Jacoby GC, Peteet DM, Griffin KL (2004) The influence of winter temperatures on the annual radial growth of six northern range margin tree species. Dendrochronologia 22:7-29. doi:10.1016/j.dendro.2004.09.005

Peterson DW, Peterson DL (2001) Mountain hemlock growth responds to climatic variability at annual and decadal time scales. Ecology 82(12):3330-3345. doi:10.1890/0012-9658

Pilcher JR, Gray B (1982) The relationships between oak tree growth and climate in Britain. J Ecol 70:297-304

Salzer MW, Hughes MK, Bunn AG, Kipfmueller KF (2009) Recent unprecedented tree-ring growth in bristlecone pine at the highest elevations and possible causes. Proc Natl Acad Sci USA 106(48):20348-20353. doi:10.1073/pnas.0903029106

Savva Y, Oleksyn J, Reich PB, Tjoelker MG, Vaganov EA, Modrzynski J (2006) Inter-annual growth response of Norway spruce to climate along an altitudinal gradient in the Tatra Mountains, Poland. Trees 20:735-746. doi:10.1007/s00468-0060088-9

Schweingruber FH (1988) Tree rings-basic and applications of dendrochronology. D. Reidel Publishing Company, Dordrecht, p 62

Serreae MC, Walsh JE, Chapin FS III, Osterkamp T, Dyurgerov M, Romanovsky V, Oechel WC, Morison J, Zhang T, Barry RG (2000) Observational evidence of recent change in the northern high-latitude environment. Clim Chang 46:159-207. doi:10. 1023/A:1005504031923

SFA (State Forestry Administration of China) (2008) National forest resources statistics (2004-2008). State Forestry Administration, Beijing, China, pp 233 (in Chinese)

Shao XM, Wu XD (1997) Reconstruction of climate change on Changbai Mountains, northeast China using tree-ring data. Quat Sci 1:76-85 (in Chinese with English abstract)

Sun Y (2011) Response of tree growth to climate change and reconstruction of summer temperature based on Larix olgensis Henry and Larix gmelinii (Rupr.) Rupr. Ph.D thesis, Graduate University of Chinese Academy of Sciences, Beijing, China

Sun Y, Wang LL, Chen J (2012) Response of tree growth to climate change and reconstruction of summer temperature based on Korean larch. J Earth Environ 3(3):889-899 (in Chinese with English abstract)

Takahashi K, Tokumitsu Y, Yasue K (2005) Climate factors affecting the tree-ring width of Betula ermanii at the timberline on Mount Norikura, central Japan. Ecol Res 20:445-451. doi:10.1007/ s11284-005-0060-y

Vaganov EA (1990) The tracheidogram method in tree-ring analysis and its application. In: Cook ER, Kairiukstis LA (eds) Method of dendrochronology. Application in the environmental sciences. Kluwer Academic Publishers, Dordrecht, pp 63-76

Walther GR, Post E, Convey P, Menzel A, Parmesan C, Beebee TJC, Fromentin B (2002) Ecological responses to recent climate change. Nature 416(28):389-395. doi:10.1038/416389a

Wang M, Tao DL (1998) Drought-tolerance of main tree species in Changbai Mountains, China. J Appl Ecol 9:7-10 (in Chinese with English abstract) 
Wang Z, Xu ZB, Li X (1980) The main forest types and their features of community structure in northern slope of Changbai mountains (1). Res For Ecosyst 1:25-32 (in Chinese with English abstract)

Wang LL, Payette S, Bégin Y (2002) Relationships between anatomical and densitometric characteristics of black spruce and summer temperature at tree line in northern Quebec. Can J For Res 32:477-486. doi:10.1139/X01-208

Wang LL, Shao XM, Huang L, Liang EY (2005) Tree-ring characteristics of Larix Gmelinii and Pinus sylvestris Var. Mongolica and their response to climate in Mohe, China. Acta Phystoecologica Sinica 29(3):380-385 (in Chinese with English abstract)

Wang LL, Duan JP, Chen J, Huang L, Shao XM (2010) Temperature reconstruction from tree-ring maximum density of Balfour spruce in eastern Tibet, China. Int J Climatol 30:972-979. doi: $10.1002 /$ joc. 2000

Wigley T, Briffa KR, Jones PD (1984) On the average value of correlated time series, with applications in dendroclimatology and hydrometeorology. J Climate Appl Meteorol 23:201-213

Wilson R, Elling W (2004) Temporal instability in tree-growth/climate response in the lower Bavarian Forest region: implications for dendroclimatic reconstruction. Trees 18(1):19-28. doi:10. 1007/s00468-003-0273-z

Wu XD, Shao XM (1996) A preliminary study on impact of climate change on tree growth using tree ring-width data. Acta Geogr Sin 51:92-101 (in Chinese with English abstract)
Yu DP, Wang SZ, Tang LN, Dai LM, Wang QL, Wang SX (2005) Relationship between tree-ring chronology of Larix olgensis in Changbai mountains and the climate change. Chin J Appl Ecol 16(1):14-20 (in Chinese with English abstract)

Yu DP, Liu JQ, Lewis BJ, Li Z, Zhou WM, Fang XM, Wei YW, Jiang SW, Dai LM (2013) Spatial variation and temporal instability in the climate-growth relationship of Korean pine in the Changbai mountains region of Northeast China. For Ecol Manag 300:96-105. doi:10.1016/j.foreco.2012.06.032

Zhang XX, Wilmking M (2010) Divergent growth responses and increasing temperature limitation of Qinghai spruce growth along an elevation gradient at the northeast Tibet Plateau. For Ecol Manag 260:1076-1082. doi:10.1016/j.foreco.2010.06.034

Zhao ZC, Luo Y (2007) Projections of climate change over northeastern China for the 21st century. J Meteorol Environ 23(3):1-4 (in Chinese with English abstract)

Zhu KZ, Wan MM (1999) Phenology. Hunan Education Press, Changsha, pp 91-94

Zhu HF, Fang XQ, Shao XM, Yin ZY (2009) Tree ring-based February-April temperature reconstruction for Changbai Mountains in northeast China and its implication for east Asian winter monsoon. Clim Past 5:661-666 